\title{
The Effect of Mycotoxin Deoxynivalenol on Haematological and Biochemical Indicators and Histopathological Changes in Rainbow Trout (Oncorhynchus mykiss)
}

\author{
Iveta Matejova, ${ }^{1}$ Helena Modra, ${ }^{1}$ Jana Blahova, ${ }^{1}$ Ales Franc, ${ }^{2}$ Petr Fictum, ${ }^{3}$ \\ Marie Sevcikova, ${ }^{1}$ and Zdenka Svobodova ${ }^{1}$ \\ ${ }^{1}$ Department of Veterinary Public Health and Welfare, Faculty of Veterinary Hygiene and Ecology, \\ University of Veterinary and Pharmaceutical Sciences Brno, Palackeho tr. 1/3, 61242 Brno, Czech Republic \\ ${ }^{2}$ Department of Pharmaceutics and Biopharmacy, Faculty of Pharmacy, University of Veterinary and \\ Pharmaceutical Sciences Brno, Palackeho tr. 1/3, 61242 Brno, Czech Republic \\ ${ }^{3}$ Department of Pathological Morphology and Parasitology, Faculty of Veterinary Medicine, \\ University of Veterinary and Pharmaceutical Sciences Brno, Palackeho tr. 1/3, 61242 Brno, Czech Republic \\ Correspondence should be addressed to Iveta Matejova; h12026@vfu.cz
}

Received 9 December 2013; Revised 27 January 2014; Accepted 27 January 2014; Published 4 March 2014

Academic Editor: Josef Velíšek

Copyright (C) 2014 Iveta Matejova et al. This is an open access article distributed under the Creative Commons Attribution License, which permits unrestricted use, distribution, and reproduction in any medium, provided the original work is properly cited.

Deoxynivalenol (DON), produced by the Fusarium genus, is a major contaminant of cereal grains used in the production of fish feed. The effect of mycotoxin deoxynivalenol on rainbow trout (Oncorhynchus mykiss) was studied using a commercial feed with the addition of DON in a dose of $2 \mathrm{mg} / \mathrm{kg}$ feed. The fish $(n=40)$ were exposed to the mycotoxin for 23 days. The trout were divided into two groups, control and experimental groups. Control groups were fed a commercial feed naturally contaminated with a low concentration of DON $(225 \mu \mathrm{g} / \mathrm{kg}$ feed); experimental groups were fed a commercial feed with the addition of DON (1964 $\mu \mathrm{g} / \mathrm{kg}$ feed). Plasma biochemical and haematological indices, biometric parameters, and histopathological changes were assessed at the end of the experiment. The experimental groups showed significantly lower values in $\mathrm{MCH}(P<0.05)$. In biochemical indices, after 23-day exposure, a significant decrease in glucose, cholesterol $(P<0.05)$, and ammonia $(P<0.01)$ was recorded in the experimental group compared to the control group. Our assessment showed no significant changes in biometric parameters. The histopathological examination revealed disorders in the caudal kidney of the exposed fish. The obtained data show the sensitivity of rainbow trout (O. mykiss) to deoxynivalenol.

\section{Introduction}

Mycotoxins are toxic secondary metabolites produced by different types of filamentous fungi. The most relevant mycotoxins to animal health and production are produced by Aspergillus, Fusarium, and Penicillium genera. Mycotoxins are thermally and chemically stable and this renders them resistant to feed manufacturing techniques [1].

Deoxynivalenol (DON), also known as vomitoxin, is a trichothecene mycotoxin produced by the Fusarium genus. Deoxynivalenol and zearalenone belong to the most prevalent mycotoxins produced by the Fusarium species [2].
Although DON is the least toxic type of trichothecene, it can cause significant harm to animals and humans [3].

Animal feed components and finished feedstuffs normally contain this mycotoxin, it is one of the most frequently found mycotoxin in cereal grains, such as wheat, barley, and corn [4].

Despite the fact that rainbow trout belongs to a carnivorous species, commercial salmonoid feeds contain plant components. Due to a decrease in the availability of fish meal for the production of aquaculture feeds, alternative protein sources need to be used in fish feed production. When we use more plant source ingredients in commercial feeds for farmed 
fish, we increase the possibility that mycotoxins contaminate those feeds [5].

Deoxynivalenol causes a broad variety of toxic effects in animals, the toxicity is well recognized in mammals. The main effect at the cellular level is the inhibition of protein synthesis through it being bound to the ribosomal subunit [6]. Chronic oral exposure induces anorexia, decreased weight gain, reduction in feed conversion, gastrointestinal hemorrhaging, inflammation, and immune system alterations. The effects of deoxynivalenol depend on dose and duration of exposure, age, species, health, and nutritional status. There are differences in sensitivity to DON contaminated feed in fish. Rainbow trout (O. mykiss) is extremely sensitive [7].

\section{Materials and Methods}

2.1. Animals. The experiment was carried out on one-yearold rainbow trout (O. mykiss) obtained from a commercial fish farm. Groups of ten fish were randomly distributed into four tanks of $200 \mathrm{~L}$ volume with dechlorinated tap water. The test was performed using a flow-through system with the bath exchanged every $12 \mathrm{~h}$ and individually aerated. A photoperiod regime of $12 \mathrm{~h}$ light: $12 \mathrm{~h}$ dark was used. Trout were acclimated for two weeks and during this acclimation were supplied twice a day with commercial pellets (BioMar, Denmark) at a total rate of $1 \%$ of body weight.

2.2. Experimental Diet. The control fish were fed a commercial diet (BioMar, Denmark) containing rapeseed oil, blood meal, fish meal, soya cake, sunflower cake, rapeseed meal, horse beans, wheat, soya concentrate, fish oil, pea proteins, vitamins, and minerals.

The experimental diet was prepared by adding DON to commercial pellets in several separate steps. The amount of $32.50 \mathrm{~g}$ of Eudragit E (Basic Butylated Methacrylate Copolymer) was dissolved in $227.50 \mathrm{~g}$ of acetone on the electromagnetic stirrer for a period of 60 minutes (solution A). $60 \mathrm{~mL}$ of this solution was put aside (solution B). Into each of the three vials containing $5 \mathrm{mg}$ of $\mathrm{DON}, 10 \mathrm{~mL}$ from the solution B was injected for the reconstitution of DON. Next, the dissolved content of these vials was added to the original solution $\mathrm{A}$. The vials were then rinsed with the rest of solution $\mathrm{B}(10 \mathrm{~mL}$ for each vial) and solutions (A and $\mathrm{B})$ were mixed together. The resultant common solution was divided into the two equal parts with the weight of $130 \mathrm{~g}$ that is equivalent to $7.5 \mathrm{mg}$ of DON.

$2470.75 \mathrm{~g}$ of pellets and $13.00 \mathrm{~g}$ of AEROSIL were added to a cubic blender and mixed for 5 minutes at $40 \mathrm{rpm}$ ("Blend A"). $130 \mathrm{~g}$ of solution with a content of $7.5 \mathrm{mg}$ of DON was uniformly and carefully poured onto the surface of mixed excipients and this moistened mixture was kneaded for 5 minutes at $40 \mathrm{rpm}$. The same procedure was performed with the "Blend B". The final mixtures were placed in a hot air dryer and dried at $50^{\circ} \mathrm{C}$ for 4 hours.

The polymer forms a specific layer on the surface of the pellets, which is formulated from the solid dispersion of the active ingredient fixed in a polymer. As a result, it is assumed
TABLE 1: Mycotoxin concentration in control and experimental feed.

\begin{tabular}{lcc}
\hline Mycotoxin contamination $\mu \mathrm{g} / \mathrm{kg}$ & Control feed & $\begin{array}{c}\text { Experimental } \\
\text { feed }\end{array}$ \\
\hline Deoxynivalenol & 225 & 1964 \\
3-Acetyldeoxynivalenol & $\mathrm{ND}^{1}$ & $\mathrm{ND}$ \\
15-Acetyldeoxynivalenol & $\mathrm{ND}$ & $\mathrm{ND}$ \\
Diacetoxyscirpenol & $\mathrm{ND}$ & $\mathrm{ND}$ \\
Fumonisin $\mathrm{B}_{1}$ & $\mathrm{ND}$ & $\mathrm{ND}$ \\
Fumonisin $\mathrm{B}_{2}$ & $\mathrm{ND}$ & $\mathrm{ND}$ \\
HT-2 toxin & $\mathrm{ND}$ & $\mathrm{ND}$ \\
T-2 toxin & $\mathrm{ND}$ & $\mathrm{ND}$ \\
Nivalenol & $\mathrm{ND}$ & $\mathrm{ND}$ \\
Ochratoxin A & $\mathrm{ND}$ & $\mathrm{ND}$ \\
Zearalenone & $\mathrm{ND}$ & 1 \\
\hline
\end{tabular}

${ }^{1} \mathrm{ND}$ : not detectable.

that there is a highly uniform content of active substance in each of the individual pellets.

2.3. Analysis of Mycotoxin. The contents of deoxynivalenol, 3-acetyldeoxynivalenol, 15-acetyldeoxynivalenol, diacetoxyscirpenol, fumonisin $\mathrm{B}_{1}$ and $\mathrm{B}_{2}, \mathrm{HT}-2$ toxin, $\mathrm{T}-2$ toxin, nivalenol, ochratoxin $A$, and zearalenone in control and experimental feed were analyzed by liquid chromatography-tandem mass spectrometry (LC-MS/MS) by Metrology and Testing Laboratory (Institute of Chemical Technology, Prague). The analyzed mycotoxin contents are described in Table 1.

2.4. Experimental Protocol. Fourty fish were divided into control $(n=20)$ and experimental $(n=20)$ groups. Control groups were twice a day fed the commercial diet used during the initial acclimation period at a total rate of $1 \%$ of body weight. Experimental groups were fed with mycotoxin-contaminated feed at a dose of $2 \mathrm{mg} / \mathrm{kg}$ feed. The samples were taken after 23 days from the beginning of the experiment. Water temperature during the test ranged from 14.0 to $15.1^{\circ} \mathrm{C}, \mathrm{pH}$ ranged from 7.9 to 8.2 , and oxygen saturation of the water ranged from 80.5 to $95.2 \%$. The physicochemical parameters of the water used in the test during the experiment were total ammonia $0.1-0.5 \mathrm{mg} / \mathrm{L}$, $\mathrm{NO}_{3}{ }^{-} 20-30 \mathrm{mg} / \mathrm{L}, \mathrm{NO}_{2}{ }^{-} 0.1-0.4 \mathrm{mg} / \mathrm{L}$, and $\mathrm{Cl}^{-} 20-25 \mathrm{mg} / \mathrm{L}$.

2.5. Haematology Profile. Blood samples were taken from each fish by puncturing the caudal vessel and stabilized with sodium heparin (50 IU per $1 \mathrm{~mL}$ of blood). Heparinized blood samples were used for the evaluation of haematological indicators including erythrocyte count (RBC), haemoglobin concentration $(\mathrm{Hb})$, hematocrit $(\mathrm{PCV})$, mean erythrocyte volume (MCV), mean erythrocyte haemoglobin $(\mathrm{MCH})$, mean corpuscular haemoglobin concentration (MCHC), and leukocyte count (WBC). Samples were determined according to Svobodova et al. [8].

2.6. Biochemical Profile. For biochemical analysis, a part of heparinized blood, after centrifugation at $855 \mathrm{~g}$ for $10 \mathrm{~min}$ 
TABLE 2: Values of haematological indices 23 days after the beginning of the experiment.

\begin{tabular}{|c|c|c|}
\hline Indices & $\begin{array}{c}\text { Control } \\
\text { mean } \pm \operatorname{SD}(n=20)\end{array}$ & $\begin{array}{c}\text { Experimental } \\
\text { mean } \pm \text { SD }(n=20)\end{array}$ \\
\hline $\mathrm{RBC}\left(\mathrm{T} \cdot \mathrm{L}^{-1}\right)$ & $1.41 \pm 0.36$ & $1.58 \pm 0.41$ \\
\hline $\mathrm{Hb}\left(\mathrm{g} \cdot \mathrm{L}^{-1}\right)$ & $76.94 \pm 12.78$ & $69.49 \pm 12.92$ \\
\hline $\operatorname{PCV}\left(L \cdot L^{-1}\right)$ & $0.30 \pm 0.06$ & $0.29 \pm 0.05$ \\
\hline MCV (fL) & $228.14 \pm 66.62$ & $198.26 \pm 53.05$ \\
\hline $\mathrm{MCH}(\mathrm{pg})$ & $57.86 \pm 16.26$ & $46.93 \pm 14.12^{*}$ \\
\hline $\operatorname{MCHC}\left(\mathrm{g} \cdot \mathrm{L}^{-1}\right)$ & $250.31 \pm 27.58$ & $235.67 \pm 22.97$ \\
\hline $\operatorname{WBC}\left(\mathrm{G} \cdot \mathrm{L}^{-1}\right)$ & $12.13 \pm 4.97$ & $14.23 \pm 3.58$ \\
\hline
\end{tabular}

Significant difference between test groups $\left({ }^{*} P<0.05\right)$.

RBC: erythrocyte count, Hb: haemoglobin concentration, PCV: haematocrit, MCV: mean erythrocyte volume, MCH: mean erythrocyte haemoglobin, MCHC: mean corpuscular haemoglobin concentration, WBC: leukocyte count.

TABLE 3: Values of biochemical parameters 23 days after the beginning of the experiment.

\begin{tabular}{|c|c|c|}
\hline Indices & $\begin{array}{c}\text { Control } \\
\text { mean } \pm \text { SD }(n=20)\end{array}$ & $\begin{array}{c}\text { Experimental } \\
\text { mean } \pm \text { SD }(n=20)\end{array}$ \\
\hline $\operatorname{ALB}\left(g \cdot L^{-l}\right)$ & $15.69 \pm 2.90$ & $15.25 \pm 2.74$ \\
\hline $\mathrm{TP}\left(\mathrm{g} \cdot \mathrm{L}^{-l}\right)$ & $37.45 \pm 5.77$ & $36.38 \pm 3.98$ \\
\hline $\mathrm{GLU}\left(\mathrm{mmol} \cdot \mathrm{L}^{-1}\right)$ & $4.84 \pm 0.79$ & $4.36 \pm 0.48^{*}$ \\
\hline $\mathrm{NH}_{3}\left(\mu \mathrm{mol} \cdot \mathrm{L}^{-1}\right)$ & $398.14 \pm 75.85$ & $280.79 \pm 57.99^{* *}$ \\
\hline TRIG $\left(\mathrm{mmol} \cdot \mathrm{L}^{-1}\right)$ & $1.90 \pm 0.40$ & $1.63 \pm 0.68$ \\
\hline LACT $\left(\mathrm{mmol} \cdot \mathrm{L}^{-1}\right)$ & $2.62 \pm 0.98$ & $2.10 \pm 0.69$ \\
\hline $\mathrm{CHOL}\left(\mathrm{mmol} \cdot \mathrm{L}^{-1}\right)$ & $6.50 \pm 1.43$ & $5.54 \pm 1.12^{*}$ \\
\hline $\operatorname{ALP}\left(\mu \mathrm{kat} \cdot \mathrm{L}^{-1}\right)$ & $1.64 \pm 0.78$ & $1.40 \pm 0.69$ \\
\hline $\operatorname{ALT}\left(\mu \mathrm{kat} \cdot \mathrm{L}^{-1}\right)$ & $0.33 \pm 0.12$ & $0.42 \pm 0.28$ \\
\hline $\operatorname{AST}\left(\mu \mathrm{kat} \cdot \mathrm{L}^{-1}\right)$ & $7.66 \pm 2.35$ & $7.71 \pm 1.85$ \\
\hline LDH-L $\left(\mu \mathrm{kat} \cdot \mathrm{L}^{-1}\right)$ & $16.57 \pm 6.50$ & $16.77 \pm 6.81$ \\
\hline $\mathrm{Ca}^{2+}\left(\mathrm{mmol} \cdot \mathrm{L}^{-1}\right)$ & $2.32 \pm 0.15$ & $2.32 \pm 0.16$ \\
\hline PHOS $\left(\mathrm{mmol} \cdot \mathrm{L}^{-1}\right)$ & $3.49 \pm 0.41$ & $3.67 \pm 0.42$ \\
\hline
\end{tabular}

Significant difference between test groups $\left({ }^{*} P<0.05 ;{ }^{* *} P<0.01\right)$.

ALB: albumins, TP: total proteins, GLU: glucose concentration, $\mathrm{NH}_{3}$ : ammonia, TRIG: triacylglycerols, LACT: lactate, CHOL: cholesterol, ALP: alkaline phosphatase, ALT: alanine aminotransferase, AST: aspartate aminotransferase, LDH: lactate dehydrogenase, $\mathrm{Ca}^{2+}$ : calcium, PHOS: inorganic phosphate.

at cooled centrifuge $\left(4^{\circ} \mathrm{C}\right)$, was used. Biochemical parameters including albumins (ALB), total proteins (TP), glucose (GLU), ammonia $\left(\mathrm{NH}_{3}\right)$, triacylglycerols (TRIG), lactate (LACT), cholesterol (CHOL), alkaline phosphatase (ALP), alanine aminotransferase (ALT), aspartate aminotransferase (AST), lactate dehydrogenase (LDH), calcium $\left(\mathrm{Ca}^{2+}\right)$, and inorganic phosphate (PHOS). Plasma biochemical indicators were measured using a biochemical automatic analyzer Konelab 20i (ThermoScientific, Czech Republic) and commercial test kits (BioVendor, Czech Republic).

2.7. Biometric Parameters. After blood sampling, the fish were stunned with a blow to the head and killed by spinal transection. Then, the biometrical indices were defined (total and standard length, body and liver weight) from which there were derived and calculated somatic parameters such as the Fultons condition factor and the hepatosomatic index. The Fultons condition factor (CF) was calculated using the formula $\mathrm{CF}=\left(\right.$ body weight $[\mathrm{g}] /$ standard length $\left.\left[\mathrm{cm}^{3}\right]\right) \times$
100. The hepatosomatic index (HSI) was calculated using the following formula: HSI = liver weight/body weight $\times 100$.

2.8. Histological Examination. The samples of gills, skin, liver, cranial, and caudal kidney and spleen of ten fish from each group were immediately fixed in buffered $10 \%$ neutral formalin. The samples were later dehydrated, embedded in paraffin wax, sectioned on a microtome at a thickness of $4 \mu \mathrm{m}$, and stained with haematoxylin and eosin $(\mathrm{H}+\mathrm{E})$. The sections were examined by light microscopy and photographed using a digital camera.

2.9. Statistical Analysis. The results of the haematological and biochemical examinations and biometric parameters were carried out with UNISTAT statistica 5.6 software. Data were first tested for normality (Shapiro-Wilk test). When necessary, logarithmic transformations were used for the analysis of variance. A one-way analysis of variance (ANOVA) and a Tukey-HSD testwere applied. If the normal distribution 
TABLE 4: Biometrical indices 23 days after the beginning of the experiment.

\begin{tabular}{lcc}
\hline Indice & Control & $\begin{array}{c}\text { Experimental } \\
\text { mean } \pm \text { SD }(n=20)\end{array}$ \\
\hline Total length & mean \pm SD $(n=20)$ & $25.89 \pm 0.85$ \\
Standard length & $26.10 \pm 1.37$ & $23.67 \pm 0.85$ \\
Body weight & $23.44 \pm 1.25$ & $185.48 \pm 29.95$ \\
Liver weight & $199.33 \pm 33.22$ & $2.92 \pm 0.66$ \\
Fultons condition factor & $2.98 \pm 0.69$ & $1.39 \pm 0.17$ \\
Hepatosomatic index & $1.54 \pm 0.17$ & $1.58 \pm 0.33$ \\
\hline
\end{tabular}

was not satisfied, a nonparametric Kruskal-Wallis test was applied. Significance was accepted at $P<0.05$.

\section{Results}

3.1. Haematology Profile. The results of the analyses of the haematological indices of both control and experimental groups after 23 days from the beginning of the experiment are presented in Table 2. The exposure caused a significant decrease of $\mathrm{MCH}(P<0.05)$ in the experimental fish. The other measured haematological indices showed no statistically significant differences between the experimental and control groups.

3.2. Biochemical Profile. The results of plasma biochemical indicators are presented in Table 3. The experimental rainbow trout exposed to the feed with deoxynivalenol showed statistically significant lower values of glucose, cholesterol $(P<0.01)$, and ammonia $(P<0.05)$ in comparison with negative control.

3.3. Biometric Parameters. The mean values of fish total and standard body length, body and liver weight, Fultons condition factor, and hepatosomatic index did not show significant differences (Table 4).

3.4. Histopathological Examination. The histopathological examination revealed severe hyaline droplet degeneration in the tubular epithelial cells (tubulonephrosis) of the caudal kidney in 9 out of 10 fish fed the diet containing DON (Figure 1). No substantial histopathological changes were demonstrated in the other tissues (gills, skin, liver, cranial kidney, and spleen).

\section{Discussion}

The study showed posttreatment changes in the haematological and biochemical profiles and histopathological changes in rainbow trout fed a commercial feed with the addition of the mycotoxin deoxynivalenol. No fish mortality was observed in the control or experimental groups during the test.

The main haematological response of rainbow trout after 23 days exposure to DON was a statistically significant decrease in $\mathrm{MCH}(P<0.05)$. The lower values of $\mathrm{MCH}$, $\mathrm{MCHC}, \mathrm{MCV}$, and $\mathrm{Hb}$ suggested that the concentration of

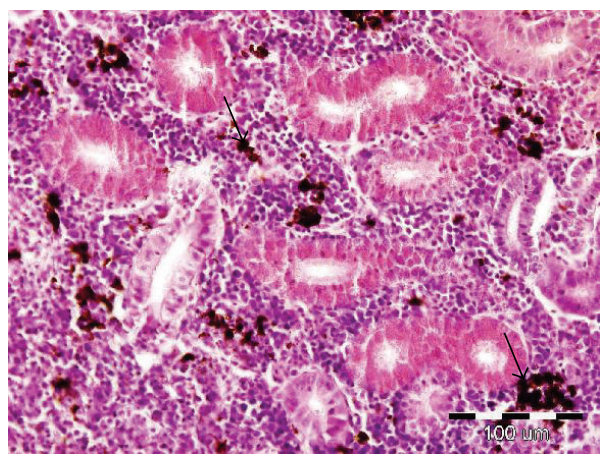

FIgURE 1: Effect of deoxynivalenol exposure on caudal kidney histology. Hyaline droplet degeneration of tubular epithelial cells (arrows). HE, 400x.

haemoglobin in red blood cells is lower due to an anaemic condition [9]. The common clinical symptoms of DON toxicity include among others gastrointestinal hemorrhaging which we demonstrated in our study (Figure 2) and might be the reason for the anaemic condition of the trout. A moderate increase in the erythrocyte count might be caused by the higher percentage of immature red blood cells in the circulation and might be the other reason for the $\mathrm{MCH}$, $\mathrm{MCHC}$, and MCV decrease in the present study [10].

The main biochemical response of rainbow trout to the effect of DON showed a decrease in glucose, cholesterol $(P<$ $0.05)$, and ammonia $(P<0.01)$ in comparison with the control groups. The lower values of these parameters might be caused by a lower intensity of metabolism. Here the effect of feeding a diet containing DON on feed intake and fish weight was observed. The fish weight was nonsignificantly lower in the DON-treated group. The decrease in feed intake could subsequently lead to a decreased intensity in nitrogen metabolism [11]. The decrease in blood glucose during the 23 days exposure can be attributed to the high utilization of glucose for hypoxic conditions and oxidation [12]. It is well established that DON consumption inhibits protein synthesis [6]. In the current study, feed with the addition of toxin caused a nonsignificant decrease in the total protein in the plasma when compared with the control fish.

We observed severe hyaline droplet degeneration in the tubular epithelial cells of the renal tubules of the caudal kidney in the experimental group. The kidney is a target organ 


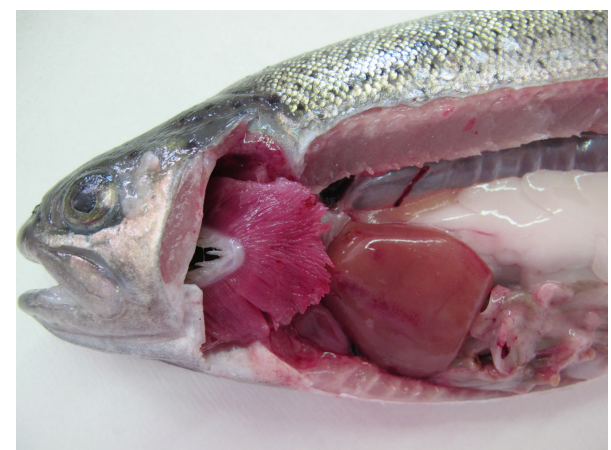

(a)

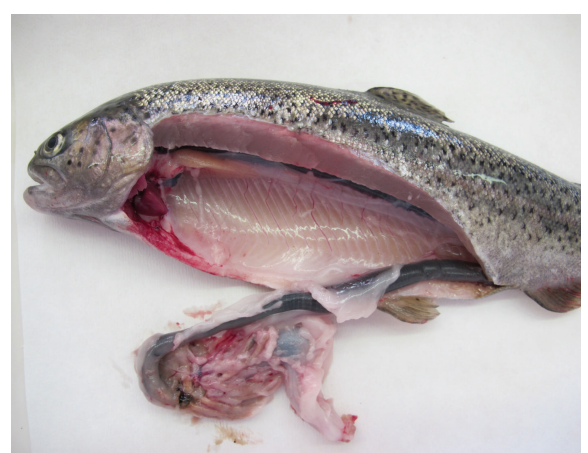

(b)

FIGURE 2: Experimental rainbow trout after exposure of DON-haemorrhages in the liver and gastrointestinal tract.

of certain toxicants; it is a major route for the excretion of foreign chemicals. On the other hand, Hooft et al. reported that deoxynivalenol caused considerable morphological changes in the liver, including subcapsular haemorrhages, subcapsular edema, altered hepatocytes, and fatty infiltration [7]. In the current study, we have demonstrated subcapsular haemorrhages in the liver in some of the fish fed diets containing the DON (Figure 2).

In conclusion, the results of the present study indicate that exposure of deoxynivalenol in a dose of $2 \mathrm{mg} / \mathrm{kg}$ feed induces significant changes in the haematological and biochemical parameters and in the histopathological examination of rainbow trout. The alterations of these parameters may provide a better understanding of the toxicological effect of mycotoxin deoxynivalenol on aquaculture fish, such as rainbow trout.

\section{Conflict of Interests}

The authors declare that there is no conflict of interests regarding the publication of this paper.

\section{Acknowledgments}

This research was supported by the Project IGA 34/2013/ FVHE and the Project KUS QJ1210013. The authors would like to thank Charles du Parc for proofreading this paper.

\section{References}

[1] C. Pietsch, S. Kersten, P. Burkhardt-Holm, H. Valenta, and S. Dänicke, "Occurence of deoxynivalenol and zearalenone in commercial fish feed: an initial study," Toxins, vol. 5, no. 1, pp. 184-192, 2013.

[2] T. D. Bucheli, F. E. Wettstein, N. Hartmann et al., "Fusarium mycotoxins: overlooked aquatic micropollutants?" Journal of Agricultural and Food Chemistry, vol. 56, no. 3, pp. 1029-1034, 2008.

[3] S. N. Wegulo, "Factors influencing deoxynivalenol accumulation in small grain cereals," Toxins, vol. 4, no. 11, pp. 1157-1180, 2012.

[4] M. Sanden, S. Jorgensen, G. I. Hemre, R. Ornsrud, and N. H. Sissener, "Zebrafish (Danio rerio) as a model for investigating dietary toxic effects of deoxynivalenol contamination in aquaculture feeds," Food and Chemical Toxicology, vol. 50, no. 12, pp. 4441-4448, 2012.

[5] B. B. Manning and H. K. Abbas, "The effect of Fusarium mycotoxins deoxynivalenol, fumonisin, and moniliformin from contaminated modly grains on aquaculture fish," Toxin Reviews, vol. 31, pp. 11-15, 2012.

[6] J. J. Pestka, H.-R. Zhou, Y. Moon, and Y. J. Chung, "Cellular and molecular mechanisms for immune modulation by deoxynivalenol and other trichothecenes: unraveling a paradox," Toxicology Letters, vol. 153, no. 1, pp. 61-73, 2004.

[7] J. M. Hooft, A. E. H. I. Elmor, P. Encarnação, and D. P. Bureau, "Rainbow trout (Oncorhynchus mykiss) is extremely sensitive to the feed-borne Fusarium mycotoxin deoxynivalenol (DON)," Aquaculture, vol. 311, no. 1-4, pp. 224-232, 2011.

[8] Z. Svobodova, D. Pravda, and H. Modra, Methods of Haematological Examination of Fish, vol. 38 of Edice Metodik, č. 122, VÚRH, Vodňany, Czech Republic, 2012, (Czech).

[9] L. Pereira, M. N. Fernandes, and C. B. Martinez, "Hematological and biochemical alterations in the fish Prochilodus lineatus caused by the herbicide clomazone," Environmental Toxicology and Pharmacology, vol. 36, no. 1, pp. 1-8, 2013.

[10] M. Saravanan, K. Prabhu Kumar, and M. Ramesh, "Haematological and biochemical responses of freshwater teleost fish Cyprinus carpio (Actinopterygii: Cypriniformes) during acute and chronic sublethal exposure to lindane," Pesticide Biochemistry and Physiology, vol. 100, no. 3, pp. 206-211, 2011.

[11] E. Zuskova, J. Machova, J. Velisek, A. Stara, Z. Svobodova, and H. K. Kroupova, "Recovery of rainbow trout (Oncorhynchus mykiss) after subchronic nitrite exposure," Acta Veterinaria Brno, vol. 82, no. 1, pp. 73-79, 2013.

[12] C. Kavitha, M. Ramesh, S. S. Kumaran, and S. A. Lakshmi, “Toxicity of Moringa oleifera seed extract on some hematological and biochemical profiles in a freshwater fish, Cyprinus carpio," Experimental and Toxicologic Pathology, vol. 64, no. 7-8, pp. 681687,2012 

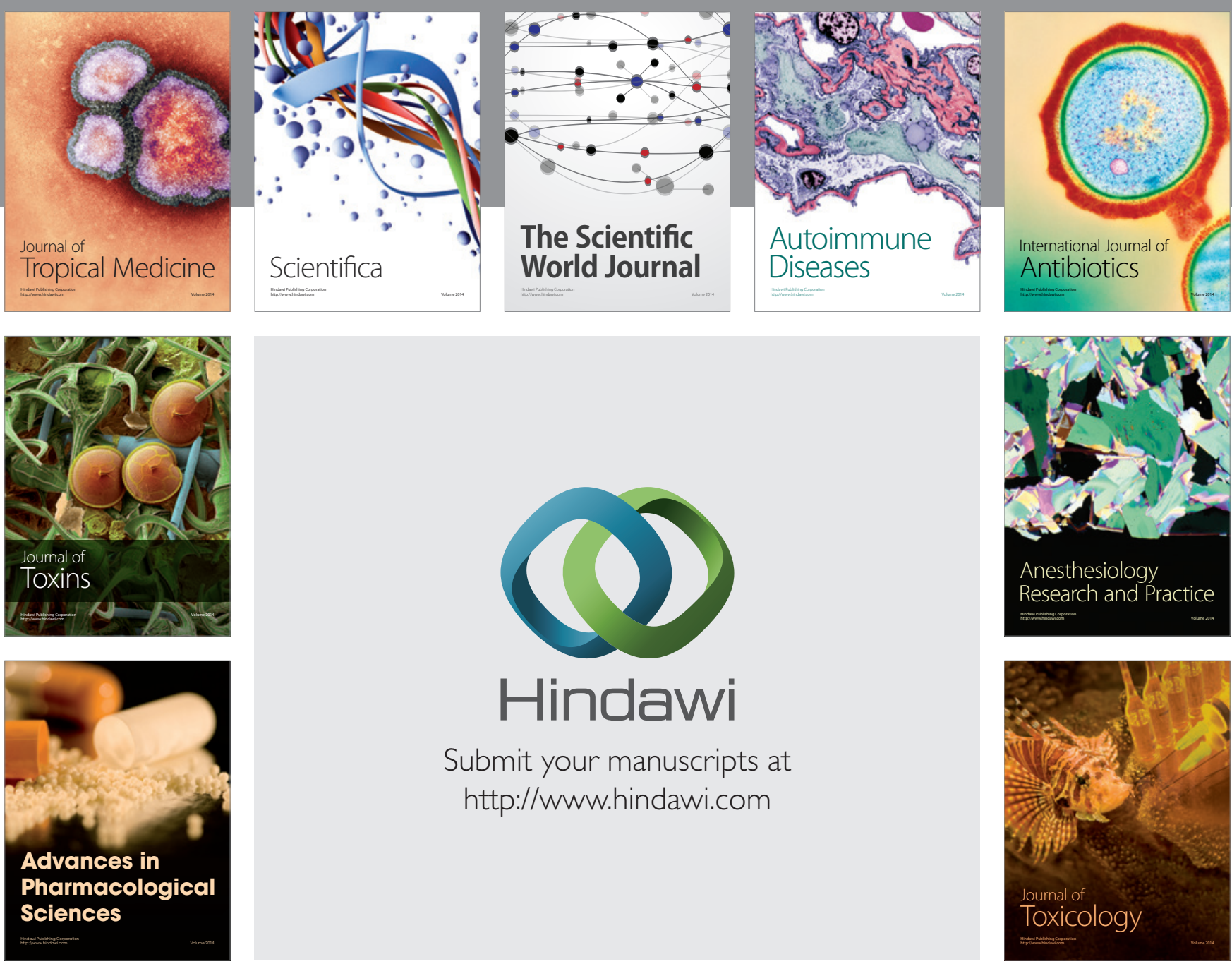

\section{Hindawi}

Submit your manuscripts at

http://www.hindawi.com
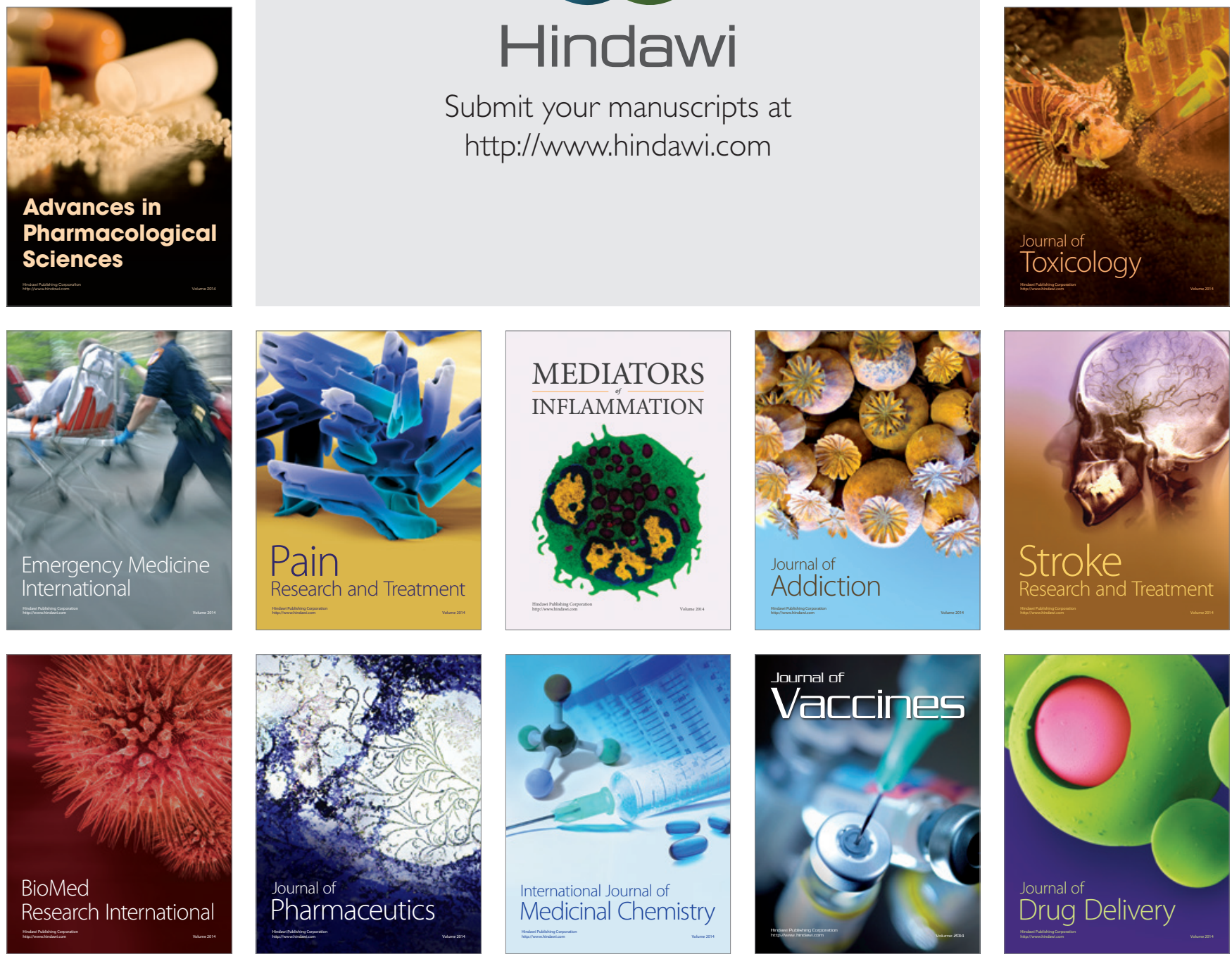